Fixed Point Theory, 22(2021), No. 2, 481-494

DOI: $10.24193 /$ fpt-ro.2021.2.32

http://www.math.ubbcluj.ro/ nodeacj/sfptcj.html

\title{
SURJECTIVITY RESULTS FOR NONLINEAR WEAKLY SEQUENTIALLY CONTINUOUS OPERATORS AND APPLICATIONS
}

\author{
AFIF BEN AMAR*, HAJER GARBOUT** AND DONAL O'REGAN*** \\ * Department of Mathematics, Sfax University, Faculty of Sciences \\ Sfax, LA 1171, 3000, Tunisia \\ E-mail: afif.benamar@ipeis.rnu.tn \\ ** Department of Mathematics, Sfax University, Faculty of Sciences \\ Sfax, LA 1171, 3000, Tunisia \\ E-mail: garbouthajer@gmail.com \\ *** School of Mathematics, Statistics and Applied Mathematics, National University of Ireland \\ Galway, Ireland \\ E-mail: donal.oregan@nuigalway.ie
}

\begin{abstract}
We introduce new surjectivity results for a couple $(T, S)$ where $T$ and $S$ are two weakly sequentially continuous operators and satisfy some homogeneity conditions. Also we present new operator quantities using the measure of weak noncompactness. Our results extend in a broad sense some theorems of Fučik, Nečas, Souček and Souček in the weak topology setting. In addition we present an application for generalized Hammerstein type integral equations.
\end{abstract}

Key Words and Phrases: Weakly sequentially continuous, $a$-homogeneous operator, measure of weak noncompactness.

2020 Mathematics Subject Classification: 47H09, 47H10, 47H30.

\section{REFERENCES}

[1] C. Angosto, B. Cascales, Measures of weak noncompactness in Banach spaces, Topol. Appl., 156 (2009), 1412-1421.

[2] J. Appell, E. De Pascale, A. Vignoli, Nonlinear Spectral Theory, De Gruyter Series in Nonlinear Analysis and Applications, Vol. 10, Berlin, 2004.

[3] O. Arino, S. Gautier, J.P. Penot, A fixed point theorem for sequentially continuous mapping with application to ordinary differential equations, Funkcialaj Ekvacioj., 27(3)(1984), 273-279.

[4] J. Banas, A. Martinón, Measures of weak noncompactness in Banach sequence spaces, Port. Math., 59(2)(1995), 131-138.

[5] J. Banas, J. Rivero, On measures of weak noncompactness, Ann. Math. Pure Appl., 151(1988), 213-224.

[6] A. Ben Amar, M. Mnif, Leray-Schauder alternatives for weakly sequentially continuous mappings and application to transport equation, Math. Meth. Appl. Sci., 33(2010), 80-90.

[7] F.S. De Blasi, On a property of the unit sphere in a Banach space, Bull. Math. Soc. Sci. Math. R.S. Roumanie, 21(1977), no. 3-4, 259-262. 
[8] K. Deimling, Nonlinear Functional Analysis, Springer-Verlag, Berlin, Heidelberg, New York, 1985.

[9] G. Emmanuele, An existence theorem for Hammerstein integral equations, Port Math., 51(1994), 607-611.

[10] W. Feng, J.R.L. Webb, Surjectivity results for nonlinear mappings without oddness conditions, Comment. Math. Univ. Carolin., 38(1997), 15-28.

[11] S. Fučik, J. Nečas, J. Souček, V. Souček, Spectral Analysis of Nonlinear Operators, Lecture Notes in Mathematics, 346, Springer-Verlag, Berlin, Heidelberg, New York, 1973.

[12] M. Furi, M. Martelli, A.Vignoli, Contributions to the spectral theory of nonlinear operators in Banach spaces, Annali Mat. Pura Appl., 118(1978), 229-294.

[13] G. Isac, S.Z. Németh, Scalar and Asymptotic Scalar Derivatives. Theory and Applications, Springer Optimization and its Applications, Vol. 13, Springer, New York, 2008.

[14] I. Meghea, Some results of Fredholm alternative type for operators of $\lambda J_{\varphi}-S$ form with applications, U.P.B. Sci. Bull., Series A, 72(2010), no. 4, 21-32.

[15] I. Meghea, Two solutions for a problem of mathematical physics equations, U.P.B. Sci. Bull., Series A, 72(2010), no. 3, 43-58.

[16] D.R. Moreira, E.V. Teixeira, Weak convergence under nonlinearities, An Acad Bras Cienc., $\mathbf{7 5}(1)(2003), 9-19$

[17] D. O'Regan, Coincidence for morphisms based on compactness principles, J. Nonlinear Sci. Appl., 11(2018), no. 9, 1096-1098.

[18] D. O'Regan, A note on the topological transversality theorem for the admissible maps of Gorniewicz, J. Nonlinear Sci. Appl., 12 (2019), no. 6, 345-348.

[19] D. O'Regan, Mönch type Leray-Schauder alternatives for maps satisfying weakly countable compactness conditions, J. Math. Computer Sci., 19(2019), no. 1, 29-34.

[20] F. Pacella, Note on spectral theory of nonlinear operators: Extensions of some surjectivity theorems of Fučik and Nečas, Czech Math J., 34(1984), 28-45.

Received: April 4, 2019; Accepted: November 21, 2019. 